\title{
Challenges and factors associated with poor glycemic control among type 2 diabetes mellitus patients at Nekemte referral hospital, western Ethiopia: cross-sectional study
}

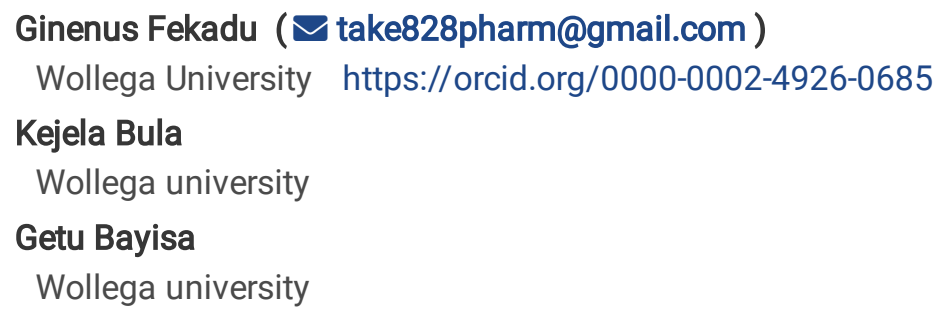

Research article

Keywords: Diabetes mellitus, Factors, Glycemic control, Type 2 diabetes mellitus, Nekemte, Ethiopia

Posted Date: August 13th, 2019

DOI: https://doi.org/10.21203/rs.2.12798/v1

License: (c) (i) This work is licensed under a Creative Commons Attribution 4.0 International License. Read Full License 


\section{Abstract}

Background: Diabetes is increasing at an alarming rate throughout the world and about $80 \%$ of diabetics' lives in developing countries. Similar to the rest of sub Saharan African countries, Ethiopia is experiencing significant burden of diabetes with increased prevalence, complications and mortality as well as life threatening disabilities. Reasons for poor glycemic control in type 2 diabetes are complex and multivariable. Hence, this study was aimed to identify challenges and factors associated with poor glycemic control among type 2 diabetes patients. Method: A hospital based cross sectional study was conducted on type 2 diabetic patients attending diabetic clinic of Nekemte Referral Hospital (NRH) from February 1 to April 30, 2018. Fasting blood glucose of last three clinic visits were obtained and the mean fasting blood glucose measurements was used to determine the level of glycemic control. Analysis included both descriptive and inferential statistics with SPSS version 20.0. Predictor variable with $\mathrm{P}<0.05$ was considered statistically significant. Result: Out of the total 228 included type 2 diabetes mellitus (DM) patients, $51.8 \%$ were males. The mean age of participants was $43 \pm 12.4$ years and $154(67.5 \%)$ were found not following their general dietary program correctly. Nearly one third, $73(32 \%)$ of participants never attended diabetic education and $52(22.8 \%)$ of the patients had greater than 10 years' duration on treatment. The majority, 148(64.9\%) of patients had poor blood glucose control. Age range of $40-60$ years $(A O R=2.01,95 \% \mathrm{Cl} 0.04-0.06, P=0.044)$, being illiterate ( $A O R=3.12,95 \% \mathrm{Cl} 1.52-8.50, P=0.001)$, having informal education only $(\mathrm{AOR}=2.28,95 \% \mathrm{Cl} 2.14-32.60, \mathrm{P}=0.024)$, longer duration of diabetes treatment $(>10$ years $)(A O R=3.94$, $95 \% \mathrm{Cl} 1.51-27.83, \mathrm{P}=0.012)$, inadequate physical exercise ( $\mathrm{AOR}=3.19,95 \% \mathrm{Cl} 1.05-19.84, \mathrm{P}=0.019)$, smoking $(\mathrm{AOR}=4.51,95$ $\% \mathrm{Cl}$ 0.00-0.50, $\mathrm{p}=0.022$ ) were independent predictors of poor glycemic control up on a multivariable logistic regression analysis. Conclusion: Nearly two third of patients had poorly controlled diabetes. Age, exercise, level of education, duration of the treatment and smoking were significantly associated with poor glycemic control. Health facilities should provide continuous education as well as barriers of glycemic control should be explored with further research.

\section{Background}

Diabetes mellitus (DM) is one of the top metabolic disorders characterized by chronic hyperglycemia caused by multiple etiologies including defects in insulin secretion, action or both [1-6]. Globally it is one of the commonest non communicable chronic-degenerative diseases $[1,7,8]$ and it is estimated that between $5-10 \%$ of the population suffer from this disease [5]. Type 2 diabetes is the predominant diabetes that accounts for $85 \%-95 \%$ of all diabetes $[2-4,9]$.

All forms of diabetes have very serious effect on health with increased risk of disabling and life threatening problems $[1-3,5$, $10]$. With this, diabetes is major cause of morbidity and mortality through both direct and indirect clinical effects [5, 10-12]. Additionally, persistent higher blood glucose level can result in serious health problems to the heart, blood vessel, kidney, nerves and other organs $[1-4,13]$. Currently, type 2 DM becomes the public health problem globally. Reasons for poor glycemic control in type 2 diabetes are complex and multivariable [14]. This inadequate glycemic control in contributes to increased rates of diabetic complications including both macrovascular and microvascular that are risk for health of the public $[9,15]$. Controlling the glycemic level is considered as the main therapeutic intervention to prevent diabetes complications and further organ damage [16].

In 2013 globally there were about 382 million people living with diabetes, with global prevalence of $8.3 \%$ [1]. According to the international diabetes federation (IDF), in 2015 approximately 415 million people were affected and by 2040 this number would reach 642 million $[17,18]$. Diabetes has historically had a higher burden in high-income countries, but the disease is growing rapidly in developing countries accounting around 80\% [1, 19]. In Africa IDF estimated that about 19.8 million adults were estimated to have diabetes and in 2018 there were more than 500 million prevalent cases of type 2 diabetes worldwide [1]. The prevalence of diabetes will increase in all countries mostly to developing countries [20]. With modernization, economic well-being and a westernized lifestyle, the burden of diabetes and its complications increases significantly in Africa [21]. As new lifestyles, imported dietary practices and globalization take roots in the developing world, diabetes and its complications are considered an epidemic in Africa [22]. Diabetes in Africa presents a rising public health challenge and many cases are probably undetected [23].

Health care systems in sub Saharan Africa (SSA) also vary widely [21]. There is poor health seeking behaviors in low resource countries because of inaccessible quality health care that increases the risk of DM complications [24]. The management DM is 
complex and good glycemic control significantly reduces the risk of complications [25]. This management of DM is not readily available in low resource settings [26, 27]. With limited resources and health budgets, along with a sharp rise in the prevalence of type 2 diabetes, staffing levels are inadequate to handle and care the patients appropriately [28]. Lack of awareness and facilities for monitoring leads to the high prevalence of diabetic complications [29]. On the other hand, lack of national guidelines, poverty and ignorance result in complications [22]. Therefore, it is serious threat to the health of individuals and the health systems capacity as whole [30].

Similar to the rest of SSA countries, Ethiopia is experiencing significant burden of diabetes with increased prevalence, complications and mortality as well as life threatening disabilities [31, 32]. World health organization (WHO) estimated that the number of cases of diabetics in Ethiopia to be 800,000 in 2000 and projected that it would increase to 1.8 million by the year $2030[8,32]$. Previous findings in Ethiopia also reported that the rate of poor glycemic control was high [17, 33, 34], most importantly due to non-compliance to existing medications [32]. Even though the prevalence of type $2 \mathrm{DM}$ is increasing rapidly in Ethiopia, data regarding glycemic control is scarce and little is known about the factors contributing for poor glycemic control [35]. Identification of the challenges and factors associated with poor glycemic control is important in order to institute appropriate interventions to improve glycemic control, prevent target organ damage and other chronic complications arising from diabetes $[16,36]$. This study was aimed to determine the status of glycemic control and identify factors associated with poor glycemic control among diabetic patients at Nekemte referral hospital (NRH).

\section{Methods And Participants Study setting and design}

The study was conducted in Nekemte Referral Hospital (NRH), located in Nekemte town at $331 \mathrm{~km}$ away from Addis Ababa to the west. NRH provides the curative and preventive services for about 80000 to 120000 populations per year. Institutional based cross sectional study was conducted from February 1 to April 30, 2018.

\section{Eligibility Criteria}

Patients who were diagnosed to have type 2 DM having at least a sixth months follow up, patients with at least three consecutive blood glucose measurements and patients who were willing to participate were included in the study. Newly diagnosed, with psychiatric disorders, pregnant women's, hospitalized and/or with critical illness and those patients cannot sign the informed consent form were excluded from the study.

\section{Sample Size and Sampling Technique}

The estimated sample size was determined by using the single proportion formula. Where $n=$ the desirable sample size $Z(a / 2)=$ the confidence interval (95\%) level of significance (1.96); $p=$ proportion of patients with poor glycemic control $d=$ precision of measurement (acceptable marginal error) $p=0.5, d=0.05$ ).

[Due to technical limitations, this equation is only available as a download in the supplemental files section.]

Where $\mathrm{N}$ is the total number of type $2 \mathrm{DM}$ patients $=507$

Using reduction formula $\mathrm{nf}=384 /(1+384 / 507)=218$.

By taking contingency of $5 \%$

$218 * 5 \%=218 * 0.05=10$

The final sample size was 228patients 
Systematic random sampling technique was employed to select the participants every 2 patients $(k=2)$ during their attendance by taking even number randomly using lottery method.

\section{Study Variables}

\section{Dependent Variable}

- Glycemic control

\section{Independent Variables}

- Socio- demographic variables: such as: age, sex, marital status, religion, educational status and income

- Medical and clinical characteristics

- Adherence to diabetic self-management

- Knowledge of blood glucose target

- Diabetes education attended

- Drug regimen

- Behavioral conditions of the patients like alcohol consumption and smoking.

\section{Data Collection Instrument and Technique}

Data was collected from the medical cards to know their blood glucose level of the last three months as well as patients were interviewed by using a semi-structured questionnaire developed by reviewing different literatures (Additional file 1: data collection tool).. The data collection format contained information on the socio-demographic characteristics, clinical characteristics of patients such as diagnosis, duration of illness, dosage regimen of medications, comorbidities, diabetes complications and blood glucose measurements.

\section{Data Processing and Analysis}

The collected data was analyzed using SPSS version 20. Descriptive statistics were calculated to describe the independent variables. Variables with $p<0.25$ on a bivariate logistic regression analysis were entered into a multivariate logistic regression analysis model to identify the independent predictors of poor glycemic control. The data was summarized using odds ratio (OR) and $95 \%$ confidence interval. Predictor variable with $p<0.05$ was considered statistically significant.

\section{Operational Definition}

Glycemic control: Based on American Diabetic Association (ADA) recommendation in to two groups [37]:

- Good glycemic control: fasting blood glucose of 70-130 mg/dl.

- Poor glycemic control: fasting blood glucose of $<70 \mathrm{mg} / \mathrm{dl}$ and $>130 \mathrm{mg} / \mathrm{dl}$.

Fasting blood sugar: blood glucose measured from venous blood after at least 8 hours of overnight fasting.

\section{Results}

\section{Socio-demographic Characteristics}


This study included 228 type 2 DM patients, of which $51.8 \%$ were males. The mean age of patients was $43 \pm 12.4$ years (ranged from 18 to 86 years). One hundred ninety-two (84.2\%) were Oromo in ethnicity and more than two third (69.7\%) of the patients were married. Less than one third (27.6\%) of the patients were illiterate and $28.9 \%$ were unemployed (table 1 ).

\section{Self-care behaviors of the participants}

Out of the study participants, 154(67.5\%) were found not following their general dietary program correctly. One hundred nighty three (84.6\%) were not having adequate physical exercise and $74(32.5 \%)$ of patients were not testing their blood glucose level adequately within the last three months of the study period. Fifteen (6.6\%) were smokers and $30(13.2 \%)$ had history of alcohol drinking (table 2).

\section{Clinical and medication characteristics}

Medications were prescribed to manage diabetes. From the total patients, 74 (32.5\%) of the patients were on anti-diabetic medication for less than five years, $102(44.7 \%)$ were on the treatment for $5-10$ years and the remaining $52(22.8 \%)$ patients had greater than 10 years' duration on treatment. About 24(10.5\%) had less than 6 times, 17(11.8) had 6-10 times and 177(77.6) had 11-12 times follow up per last year. One hundred seventy-nine (78.5\%) of the study participants didn't know target blood glucose level for diabetes management. Nearly one third, 73(32\%) of respondents never attended diabetic education. Majority, 190(83.3) of the patients had less than two times diabetic education session per last year and $53(22.4 \%)$ of them had less than ten times follow up to the clinic per year. Seventy-five (33\%) of patients had at least one type of comorbidity. Hypertension was the major type of comorbidity detected in $60(26.3 \%)$ patients. The most common anti-diabetic drug was oral anti-diabetic agents 136(59.6\%) followed by the combination treatment of oral hypoglycemic agents and insulin comprising $53(23.2 \%)$. About $77(33.8 \%)$ of the patients were taking the combination of metformin and glibenclamide. More than half, $133(58.3 \%)$ of the patients were on combination therapy (two drug treatment) and the remaining patients were on monotherapy. Seventy-five (32.9\%) patients had concomitant medication for the treatment of comorbidities. Enalapril was the most common prescribed concomitant medication.

\section{Glycemic control and factors affecting glycemic control}

Fasting blood sugar records of the last three clinic visits were obtained from patients' medical cards and the mean was used to determine the level of glycemic control. With this, the majority $148(64.9 \%)$ of patients had poor blood glucose control. Out of uncontrolled glycemic control, $22(9.60 \%)$ and 126(55.3\%) had blood glucose level $<70 \mathrm{mg} / \mathrm{dl}$ and $>130 \mathrm{mg} / \mathrm{dl}$, respectively. Age, educational level, duration of diabetes treatments, physical exercise and smoking had a significant association with glycemic control up on a multivariable logistic regression analysis.

The relative odds of poor glycemic control was two times ( $\mathrm{AOR}=2.01,95 \% \mathrm{Cl} 0.04-0.06, \mathrm{P}=0.044)$ higher among patients in age range of 40-60 years compared to the ages of greater than 60 years. The association of poor glycemic control was about three $(\mathrm{AOR}=3.12,95 \% \mathrm{Cl} 1.52-8.50, \mathrm{P}=0.001)$ and two times $(\mathrm{AOR}=2.28,95 \% \mathrm{Cl} 2.14-32.60, \mathrm{P}=0.024)$ higher among patients who were illiterate and with informal education, respectively, than those with college/higher educational levels. Compared to those who had shorter duration of diabetes treatment ( $<5$ years), participants who had longer duration of diabetes treatment (>10 years) were about four times $(\mathrm{AOR}=3.94,95 \% \mathrm{Cl} 1.51-27.83, \mathrm{P}=0.012)$ more likely to have poor glycemic control. Compared to respondents who had adequate physical exercise, respondents who had inadequate physical exercise were about three times $(\mathrm{AOR}=3.19,95 \% \mathrm{Cl} 1.05-19.84, \mathrm{P}=0.019)$ more likely to have poor glycemic control. On the other hand, the odds of poor glycemic control was 4.5 times higher among smokers ( $A O R=4.51,95 \% \mathrm{Cl} 0.00-0.50, \mathrm{p}=0.022)$ compared to nonsmokers (table 3).

\section{Discussion}


The study found that overall glycemic control among the study subjects was far below the internationally recommended standards and guidelines. Only fasting blood sugar was used to monitor glycemic control in this hospital similar to previous study done in Addis Ababa, Ethiopia [38]. This was due to unavailability of the service and high cost of the glycated hemoglobin (HbA1c) determination in the governmental hospitals of Ethiopia. In developed countries glycemic management is primarily assessed with the $\mathrm{A} 1 \mathrm{C}$ test that reflects average glycaemia over approximately 3 months [39].

Glycemic control knowledge is very crucial to control blood sugar level. Majority of the patients didn't have sufficient knowledge of target blood glucose level for diabetes management. This indicates that patients depend on their health care provider's support to control and treat their diabetes. It is great problem for patients to take appropriate interventions without knowing target level of diabetes management. Unless patients understand the chronic progressive nature of the disease and actively involved in their management process, it would be difficult to achieve adequate glycemic level.

The majority, $148(64.9 \%)$, of patients had poor blood glucose control. Proportion of poor glycemic control was comparably similar with the studies conducted in Amman Jordan[11], Shanan Gibe hospital southwest Ethiopia[33], Dessie referral hospital northeast Ethiopia [34], Jimma university teaching hospital southwest Ethiopia [35] and university of Gondar referral hospital [40] where the rate of poor glycemic control was $65.1 \% 59.2 \%, 70.8 \%, 70.9 \%$ and $64.7 \%$, respectively. But our finding was lower when compared to previous studies conducted at Jimma university specialized hospital [41] and in MGM medical college, Navi Mumbai [36] where $81.9 \%$ and $91.8 \%$ of patients hadn't achieved adequate level of glycemic control, respectively. The study also revealed that poor glycemic control was higher when compared with study conducted in Najran armed force hospital [42], Ambo hospital [43] and Ayder referral hospital [9] that $22 \%, 50 \%$ and $48.7 \%$ of the patients have poor glycemic control, respectively. Studies from western countries shown similar finding with respect to the quality of diabetes care and the glycemic outcome among the diabetic population [44-46], which highlights the progressive difficulty of maintaining optimal glycemic control in patients with type 2 diabetes as only few patients achieve the desired glycemic goals $[44,46]$. The possible reason for this difference could be due to difference in knowledge of glycemic control, available health service, income, behavioral and clinical characteristics of the patients as well as lack of uniform guidelines. These finding highlights the need to work more on appropriate management of diabetes, as maintaining optimum glycemic control is main therapeutic goal for all patients.

In this study, the mean age of the type 2 DM patients was about $43 \pm 12.4$ years, with the majority of them in the age group of $41-$ 60 years. Patients in age range of 41-60 years constitute a higher proportion of patients with poor glycemic control when compared with those in the age group of $<40$ years and $>60$ years similar to previous study conducted in Dar es Salaam [16]. The presence of association between age and poor glycemic control in our study was consistent with previous study findings $[9,11$, 16] which reported that younger age was associated with poor glycemic control. But study done in MGM medical college, India revealed that age was not statistically significantly associated with glycemic control [36]. The observed variation of association between age and poor glycemic control could be explained by the differences in population pyramids and distribution of age in different studies. Younger individuals are more likely to have more barriers to self-management behaviors such as healthy lowfat diet, glucose testing and compliant with their diet and medications.

The young age of patients in this study was striking. Previously, type 2 DM was predominantly a disease of middle-aged and older people. However recent reports indicated that type 2 DM is becoming an increasingly prevalent disorder among young's around the world in all ethnicities driven by lifestyle factors [47-49]. This is linked to the global economic growth and changes in lifestyle and dietary habits. This rising is in parallel with the incidence of overweight and obesity, suggesting a possible causal relationship, particularly when the obesity is central and in relation to decreased physical activity [47-50]. Genetic and familial factors, low birth weight, fetal environmental factors, particularly maternal gestational diabetes and intrauterine growth retardation, and lack of physical activity during childhood and adolescence were the other contributing factors. All of these are associated with insulin resistance, although decreased insulin secretion is also required [47, 48,51]. Despite the young age of onset and shorter duration of diabetes, this group tends to develop diabetes related complications such as nephropathy and CVD early in the disease process [52]. Type 2 DM in young's can be controlled to a large extent through lifestyle modification measures. It is important that to screen this disease condition, and identify the at-risk cases [50]. Patient and family education for a young person with T2DM is very important and will focus on behavioral changes (diet and activity) [51]. Unfortunately we 
haven't assessed the body mass index (BMI) of the patients to identify the nutritional status of the patients. Thus, in our study we haven't identified the real cause of elevated proportion of young type 2 DM patients.

There was almost equal proportions of the patients among the two sexes (51.8\% versus $48.2 \%)$. Compared to some previous studies the proportion of the women was low in our study finding. The step rise and associated complications of type 2 DM go along with mounting evidence of clinically important sex and gender differences. Large sex-ratio differences across countries are observed. Diversities in biology, culture, lifestyle, environment, and socioeconomic status impact differences between males and females in predisposition, development, and clinical presentation. Genetic effects and epigenetic mechanisms, nutritional factors and sedentary lifestyle affect risk and complications differently in both sexes [53]. In the first half of the last century the prevalence of type $2 \mathrm{DM}$ was higher among women than among men, but this trend has shifted, so more men than women are now diagnosed with type 2 diabetes. This change in the gender distribution of type 2 diabetes is mainly caused by a more sedentary lifestyle particularly among men, resulting in increased obesity [54]. Men are more insulin resistant than women, which can be explained by their higher proportion of visceral and hepatic fat compartments [54,55]. Even one meta-analysis demonstrated that, compared with the corresponding women, the men in eastern, middle and southern Africa had a significantly higher prevalence of impaired fasting glycaemia [56]. In our setup economic issue is a challenge for both sexes to follow the medical care. Thus the prevalence of diabetes mellitus was found to be lower or higher in women than in men when analyzed by African sub regions. Sex-based differences in the relationship between individual socioeconomic status and diabetes mellitus still need to be investigated in developing countries.

Being illiterate and having lower education was independently associated with poor glycemic control which complies with previous studies $[19,34,35,41]$. This was unlike to study in Dares Salaam were education of patients was not associated with glycemic control [16]. Low education level is associated with poor health, low glycemic diabetes knowledge, low selfmanagement behaviors, lower self-efficacy and lower continuity of care. Additionally, shortage of availability of health service may also negatively affect glucose control. Moreover, higher education level is correlated with better knowledge of diabetes complications and greater adherence to diet and medications.

Duration of first diagnosis of $>10$ years was significantly associated with poor glycemic control which was consistent with previous studies reported that the length of duration of diabetes associated with poor glycemic control $[11,36,44,57,58]$. Patients with shortest duration of disease may be relatively adherent to medication and recommended diets. From the pathophysiology of the disease, longer duration of diabetes is associated with progressive impairment of insulin secretion, increased insulin resistance and eventually decrease in insulin secretion. In earlier disease stages, the task of reaching glycemic goal is aided by residual ß-cell function, whereas in advanced stages, there is progressively less endogenous insulin secretion $[11,14,16]$. Therefore, as the disease progresses most patients require an increase in their medications to maintain glycemic control. However, as study done in Shanan Gibe Hospital Southwest Ethiopia, diabetes treatment for 5-10 years was one independent predictors of glycemic control among type 2 diabetes patients [33] due to poor medication adherence, poor lifestyle conditions and failure to adhere to regular follow up at diabetes clinic.

The storage and qualities of the drugs are critical issue in Africa including our setup. Due to pocket expense, there were situations where some patients couldn't able to afford the cost and failed to purchase the drugs that leads to noncompliance. For example, most patients couldn't able to store insulin below $8^{0} \mathrm{C}$ due to lack of refrigerators and other storage facilities. Even the storage of oral medications didn't comply with the recommended standard guidelines. While some of the participants' antidiabetic medications-related perceptions appeared to be similar to those expressed by western patients, there were perceptions that were different including the exaggerated concerns towards the medications could potentially lead to intentional nonadherence and affect health outcomes. Consensus was that some patients do not want to take medication long-term. Back home, medication was used on a short-term basis to 'cure' something and then it was stopped. Taking medication over a long period of time as a means to prevent damage from chronic disease may be unfamiliar and difficult to understand. There are several recurring reasons people did not want to take medication including a generalized fear of side effects. Even patients often stopped taking medications without informing their health care provider. 
Regarding the feeding habits, patients in our country doesn't flow the dietary recommendation as physicians ordered, because of economy of our patients to afford it. The typical diet the patients using were mostly 'injera' prepared from locally produced teff, sorghum and maize. There is no quality of water as most of rural patients were using from groundwater/well water, but urban patients were using tap water. Majority of the patients didn't have devices (glucometer) to monitor glucose in blood. Some were illiterate, some patients failed to afford and others were inaccessible to the devices. This is even the current challenge in our country.

Although physical activity was shown to be protective among patients with type 2 DM [19], only a small proportion of patients with type $2 \mathrm{DM}$ were participated in regular planned physical activity. There was statistically significant differences between patients who did not perform regular physical activity in terms of glycemic control and those who were participating in regular physical exercise. Study by Alramadan M etal in Saudi Arabia reported that low level of physical activity was one independent risk factors for inadequate glycemic control [59] and study in Ayder referral hospital, Mekelle town, Ethiopia showed that patients participated in regular exercise were less likely to be poorly controlled [9]. However, the lack of a relationship between exercise behavior/ physical activity and poor glycemic control was observed in other studies $[14,16,19]$. This difference possibly explained by difference in study population, culture, economy, environment and sample size. Most patients in rural walk in majority of their daily life for occupation related, but this was not associated with aerobic/ planned physical activity. Some patients were not voluntary to do planned aerobic physical activity as physician ordered (at least 150 minutes per week). This was due to most patients doesn't have time, have no experience to do, fail to understand required procedures and lack of field area to practice it.

On the other hand, the odds of poor glycemic control was four times higher among smokers compared to nonsmokers. This complies with previous study that reported current smokers had an increased risk of poor glycemic control [60]. As well as Willi $\mathrm{C}$ et al reported that the risk of diabetes is shown to be higher by $45 \%$ in smokers than among nonsmokers [61]. Additionally study by Ohkuma $\mathrm{T}$ et al reported that $\mathrm{HbA} 1 \mathrm{c}$ levels increased progressively with increases in both number of cigarettes per day and pack-years of cigarette smoking compared with never smokers. Smoking and its cessation showed dose- and time-dependent relationship with glycemic control and insulin resistance in patients with type 2 diabetes mellitus [62]. Smoking increases the risk of central obesity and insulin resistance as well as nicotine exposure has several other deleterious effects [63].

There different challenges in glycemic control in Africa including our country Ethiopia. Very few countries in sub-Saharan Africa can afford to screen and treat the complications of diabetes [64]. This resource-limited countries are unable to provide even minimum care in some instances [21]. Poorly skilled health care staff, delay in seeking medical attention and lack of access to affordable drugs contribute to the high rate of diabetes-related mortality [29,65]. Even the newer classes of drugs are unaffordable for the majority of the population. One of the major challenges facing insulin-treated patients in sub-Saharan Africa is the lack of a constant supply of insulin at affordable cost [66]. This supply of insulin is erratic, even at large hospitals and the prospects for people with diabetes are poor $[67,68]$.

Achieving glycemic control in patients with diabetes is of paramount importance to their overall health and survival [47]. Poor glycemic control is a risk factor to both micro and macro vascular complications of diabetes and a major factor in the burden of the disease [23]. Self-management is a key element for the proper management, but strategies are currently lacking in developing countries context [22,30]. Self-monitoring of blood glucose was rarely used, mainly because of the cost of testing supplies in $90 \%$ and the unavailability of testing supplies in $70 \%$ of the countries in Africa [21]. Even though, patients with diabetes often struggle to achieve glycemic control targets, self-monitoring of blood glucose, physical activity and risk reduction behavior are insufficient [30,47]. Even if treatment guidelines are available, they are hardly used and are not up to date [21]. Even in many European countries patients may find this degree of disease management difficulty, with a corresponding negative impact on adherence and glycemic control [44].

In general there are parcel of problems encountered in the management of diabetes in sub-Saharan Africa. This includes problems related to diagnosis, medical care, drug supply, monitoring, diabetes education, cost of medication, dietary advice and management infections associated with diabetes. Additionally, poor patient attendance, short consultation time, inadequate infrastructure, poor evaluation of complications of diabetes, poor record keeping, disproportionate distribution of health care facilities and lack of adequately trained health care professionals to care and treat diabetic patients are top challenges observed 
African countries including our country. In our setup patients are not supplied with medicaments, rather they purchase from the hospital by their own expense. If drugs are not available or in case of stock out from the governmental hospital pharmacy, patients purchase drugs from the private and community pharmacies. Rare patients that have written certificate for unable to purchase the medications, the government supply freely. Due to pocket expense, there are conditions where some patients couldn't able to afford the cost and fail to purchase the drugs that leads to noncompliance. Adequate knowledge of the overall burden of diabetes in high-risk populations and countries is a prerequisite for effective diabetes health care delivery. This requires urgent targeted interventions to improve glycemic control in this population and prevent chronic complications.

\section{Limitation of study}

The study was cross-sectional study design, where causal relationship between the independent and dependent variables cannot be established. Medication adherences, dietary intake, blood glucose testing, smoking status and physical activities were obtained by self-report and may be limited by recall and social desirability bias. None of the patients had HbA1c determination; which is gold standard to determine patient's 'glycemic level'. Absence of HbA1c determination directly compromise quality service given for the patients; since FBS reflect the glycemic status of the one spot. But measurement of glycated hemoglobin (HBA1c) would show the rate of glycemic control over 3 month's period. Additionally BMI was not presented that would provide specific insight into uniqueness of this population especially regarding nutritional status of the patients.

\section{Conclusion}

This study revealed that about two third of patients had poor glucose level. Age, exercise, level of education, duration of the treatment and smoking were significantly associated with poor glycemic control among type 2 diabetes patients. Thus patients should know rationales of self-care activities and take appropriate intervention accordingly. Health sectors should provide continues health education that emphasizes on behavioral lifestyle modification with importance of encouraging physical activity and cessation of smoking. Patient's education plays key role to control the glycemic control, favor treatment success, reduce adverse drug event and prevent further complication of diabetes. To educate the patient the level of education of the patient, resource and available materials influence the scope of the education. The area of education should focus on proper utilization of blood glucose device, foot care hygiene, weight loss for obese and overweight, balanced diet, adherence to medication and prevention of DM complications. Culturally appropriate educational like fact sheets, toolkits, booklets, CDs, DVDs, pamphlet, webinars and other materials can be used. Additionally free, colorful, low-literacy patient handouts related do diabetes can be used. More attention should be focused to patients with longer duration of disease, and for patients who have not educated. Barriers of glycemic control should be explored since this study does not look at barriers. We recommend further population and longitudinal studies to assess determinants poor glycemic control over the period of time.

\section{Abbreviation}

ADA: American diabetic association; AOR: Adjusted odds ratio; BGL: Blood glucose level; COR: Crude odds ratio; DM: Diabetic mellitus; FBS: Fasting blood sugar; NRH: Nekemte Referral Hospital; OHAs: Oral Hypoglycemic agents; WHO: World Health Organization

\section{Declarations}

\section{Acknowledgement}

We would like to thanks Wollega university institute of health sciences, Department of pharmacy for logistic support to conduct the research. We are grateful to staff members of $\mathrm{DM}$ clinic of $\mathrm{NRH}$, data collectors and study participants for their cooperation in the success of this study.

Funding: Not applicable 
The datasets used and/or analyzed during the current study are available from the corresponding author on reasonable request.

\section{Authors' Contributions}

GF contributes in the design the study, analysis and write up of the manuscript. KB and GB made the conception of study design and write up of the manuscript. All authors critically revised the manuscript and have approved the final manuscript.

\section{Ethics approval and consent to participate}

Ethical clearance was obtained from the Institutional Review Board (IRB) of Wollega University, Institute of health. Verbal consent was obtained from responsible bodies of the hospital and DM clinic of the hospital prior to the interview and reviews of the patient data. Written informed consent was obtained from patients to participate in this study was obtained after comprehensive explanation of the purpose and procedure of the study.

Competing Interests: The authors declare that they have no competing interests.

Consent for publication: Not applicable. No individual person's personal details, images or videos are being used in this study Publisher's Note

Springer Nature remains neutral with regard to jurisdictional claims in published maps and institutional affiliations.

\section{References}

1. Cho N, Whiting D, Guariguata L, Montoya PA, Forouhi N, Hambleton I, et al. International diabetes federation atlas report: Global burden of diabetes. Belgium, Brussels; 2013.

2. Craig M, Hattersley A, Donaghue KC. Definition, epidemiology and classification of diabetes in children and adolescents. Pediatric diabetes.2009; 10 (12):3-12.

3. Nathan DM, Buse JB, Davidson MB, Ferrannini E, Holman RR, Sherwin R. Medical Management of Hyperglycemia in Type 2 Diabetes: A Consensus Algorithm for the Initiation and Adjustment of Therapy. Diabetes Care. 2009; 32(1):193-203.

4. Center of disease prevention and control. National diabetes fact sheet: general information and national estimates on diabetes in the United States. Atlanta, U.S. Department of Health and Human Services CDC, and Prevention; 2005.

5. Leon Litwak, Su-Yen Goh, Zanariah Hussein, Rachid Malek, Vinay Prusty etal. Prevalence of diabetes complications in people with type 2 diabetes mellitus and its association with baseline characteristics in the multinational A1chieve study. Diabetol Metab Syndr. 2013; 5: 57

6. World Health Organization. Diagnosis and classification of diabetes mellitus and its complications part 1: diagnosis and classification of diabetes mellitus world. 1999.

7. Ogurtsova K, da Rocha Fernandes J.D, Huang Y., Linnencamp U, Guariguata L, Cho N. H., Cavan D, Shaw J. E. and Makaroff L. E. IDF Diabetes Atlas: Global estimates for the prevalence of diabetes for 2015 and 2040. Diabetes Research and Clinical Practice. 2017; 128: 40-50.

8. Abdulfatai B. Olokoba, Olusegun A. Obateru, and Lateefat B. Olokoba. Type 2 Diabetes Mellitus: A Review of Current Trends. Oman Med J. 2012; 27(4): 269-273.

9. Eticha Tadele, Mulu Abrahaley, Gebretsadik, Hailekiros, Kahsay Getu, Ali Dagim, Rajeshwar Yerra. Factors Associated with Poor Glycemic Control in Type 2 Diabetic Patients Investigated at Ayder Referral Hospital, Mekelle, Ethiopia. Ijppr. Human. 2016; 6 (3): 160-171

10. Genetics and Diabetes, published in "Reviews in Endocrine and Metabolic Disorders 5.1 (2004): 25-36." (Available at http://docplayer.net/5742509-Genetics-and-diabetes.html). 
11. Khattab M, Khader YS, Al-KhawaldehA, Ajlouni K. Factors associated with poor glycemic control among patients with Type 2 diabetes. Journal of Diabetes and its complication.2010; 24:84-9.

12. Koro, C. E., Bowlin, S. J, Bourgeois, N and Fedder, D. O. Glycemic control from 1988 to 2000 among US adults diagnosed with type2 diabetes: A preliminary report. Diabetes Care. 2004; 27(1), 17-20.

13. WHO diabetes fact sheet October, 2013. Report No.: 312.

14. Pamungkas RA, Hadijah St, Mayasari A, Nusdin. Factors Associated with Poor Glycemic Control among Type 2 Diabetes Mellitus in Indonesia. Belitung Nursing Journal. 2017; 3(3):272-280.

15. Haghighatpanah Mohammad, Nejad Amir, Haghighatpanah Maryam, Thunga Girish,Mallayasamy Surulivelrajan. Factors that Correlate with Poor Glycemic Control in Type 2Diabetes Mellitus Patients with Complications. Osong Public Health Res Perspect. 2018;9(4):167-174

16. Kamuhabwa Appolinary R and Charles Emmanuel. Predictors of poor glycemic control in type 2 diabetic patients attending public hospitals in Dar es Salaam. Drug, Healthcare and Patient Safety. 2014;6: 155-165

17. International Diabetes Federation. IDF diabetes atlas. 7th ed. Brussels: International diabetes federation: 2015.

18. Ogurtsova K, Da Rocha Fernandes JD, Huang Y et al. IDF Diabetes Atlas: Global estimates for the prevalence of diabetes for 2015 and 2040. Diabetes Res Clin Pract 2017; 128: 40-50.

19. Silva Débora Gonçalves da, Simeoni Luiz Alberto, Amato Angélica Amorim. Factors Associated with Poor Glycemic Control among Patients with Type 2 Diabetes in the Southeast Region of Brazil. International Journal of Diabetes Research. 2018; 7(2): $36-40$

20. Kaiser Amy Bradshaw, Zhang Nicole and Pluijm Wouter Van der. Global Prevalence of Type 2 Diabetes over the Next Ten Years (2018-2028). Diabetes 67(Supplement 1):202-LB

21. Mbanya JC, Ramiaya K. Diabetes Mellitus. In: Jamison DT, Feachem RG, Makgoba MW, et al., editors. Disease and Mortality in Sub-Saharan Africa. 2nd edition. Washington (DC): The International Bank for Reconstruction and Development / The World Bank; 2006. Chapter 19. Available from: https://www.ncbi.nlm.nih.gov/books/NBK2291/.

22. Azevedo M, Alla S. Diabetes in sub-saharan Africa: kenya, mali, mozambique, Nigeria, South Africa and zambia. Int $\mathrm{J}$ Diabetes Dev Ctries. 2008;28(4):101-108. doi:10.4103/0973-3930.45268.

23. Onodugo, O. D., Ezeala-Adikaibe, B. A., Anyim, O. B., Onodugo, P., Anyim, I. N., Mbadiwe, N. C., Young, E., Abonyi, M., Anigbo, G., Ulasi, I. and Okechukwu, U. C. Glycemic Control among Medical Outpatients in Enugu: A Cross Sectional Survey. Journal of Diabetes Mellitus. 2019; 9, 50-61. https://doi.org/10.4236/jdm.2019.92006.

24. Nwafor A, Owhoji A. Prevalence of diabetes mellitus among Nigerians in Port Harcourt correlates with socio-economic status. J Appl Sci Environ Manag. 2001. 5(1): 75-77.

25. Alberti H, Boudriga N, Nabli M. Primary care management of diabetes in a low /middle income country: a multi-method, qualitative study of barriers and facilitators to care. BMC Family Practice. 2007. 8:63. www.biomedcentral.com/14712296/8/63.

26. Omiepirisa Yvonne Buowari (January 23rd 2013). Diabetes Mellitus in Developing Countries and Case Series, Diabetes Mellitus - Insights and Perspectives, Oluwafemi O. Oguntibeju, IntechOpen, DOI: 10.5772/50658. Available from: https://www.intechopen.com/books/diabetes-mellitus-insights-and-perspectives/diabetes-mellitus-in-developing-countriesand-case-series.

27. Edo AE, Adediran OS. Carbohydrates in diabetic diet in Nigeria: is it evidence based? Nig J Gen Pract. 2006. 7(9): 19-23.

28. WHO (World Health Organization).2000. The World Health Report 2000-Health Systems: Improving Performance. Geneva: WHO.

29. Swai A. B. M., Lutale J., McLarty D. G. Diabetes in Tropical Africa: A Prospective Study 1981-7: Characteristics of Newly Presenting Patients in Dar es Salaam, Tanzania 1981-7. British Medical Journal. 1990; 300:1103-7.

30. Stephani V, Opoku D, Beran D: Self-management of diabetes in Sub-Saharan Africa: a systematic review. BMC public health 2018, 18(1):1148.

31. Nigatu T. Epidemiology, complications and management of diabetes in Ethiopia: a systematic review. J Diabetes. 2012; 4(2):174-80. 
32. Desse TA, Eshetie TC, Gudina EK. Predictors and treatment outcome of hyperglycemic emergencies at Jimma UniversitSpecialized Hospital, southwest. BMC Res Notes. 2015;8 (553):1-8.

33. Yigazu Daniel Miteku and Desse Tigestu Alemu. Glycemic control and associated factors among type 2 diabetic patients at Shanan Gibe Hospital, Southwest Ethiopia. BMC Res Notes. 2017; 10:597

34. Fiseha Temesgen, Alemayehu Ermiyas, Kassahun Wongelawit, Adamu Aderaw and Gebreweld Angesom. Factors associated with glycemic control among diabetic adult out-patients in Northeast Ethiopia. BMC Res Notes. 2018; 11:316

35. Kassahun Tefera, Eshetie Tesfahun and Gesesew Hailay. Factors associated with glycemic control among adult patients with type 2 diabetes mellitus: a cross-sectional survey in Ethiopia. BMC Res Notes. 2016; 9:78

36. Kakade Ashutosh A, Mohanty Ipseeta R and Rai Sandeep. Assessment of factors associated with poor glycemic control among patients with Type II Diabetes mellitus. Integr Obesity Diabetes, 2018; 4(3): 1-6

37. American Diabetes A. Standards of medical care in diabetes. Diabetes care. 2005; 28 (suppl 1):s4-s36.

38. Yohannes T. E. The magnitude of glycemiccontrol and its associated factors among patients with type 2 diabetes at Tikur Anbessa specialized hospital, Addis Ababa, Ethiopia, 2015

39. Li J, Chattopadhyay K, Xu M, Chen Y, Hu F, Chu J, Li L: Glycaemic control in type 2 diabetes patients and its predictors: a retrospective database study at a tertiary care diabetes centre in Ningbo, China. BMJ Open 2018, 8(3):e019697.

40. Abebe SM, Berhane Y, Worku A, Alemu S, Mesfin N. Level of sustained glycemic control and associated factors among patients with diabetes mellitus in Ethiopia: a hospital-based cross-sectional study. Diabetes Metab Syndr Obes. 2015; 27(8):65-71.

41. Hailu E, Mariam WH, Belachew T, Birhanu Z. Self-care practice and glycaemic control amongst adults with diabetes at the Jimma University Specialized Hospital in south-west Ethiopia: A cross-sectional study. Afr J Prim Health Care Fam Med. 2012; 4(1):311.

42. Harrabi, I, Al Harbi, F and Al Ghamdi, S. Predictors of Glycemic Control among Patients with Type 2 Diabetes in Najran Armed Forces Hospital: A Pilot Study. Journal of Diabetes Mellitus. 2014; 4 (2), 141-147..

43. Woldu MA, Wami CD, Lenjisa JL, Tegegne GT, Tesfaye G, Dinsa H. Factors Associated with Poor Glycemic Control among Patients with Type 2 Diabetes Mellitus in Ambo Hospital, Ambo; Ethiopia. Endocrinol Metab Synd. 2014; 3: 143.

44. de Pablos-Velasco P, Parhofer KG, Bradley C, Eschwege E, Gonder-Frederick L, Maheux P, Wood I, Simon D: Current level of glycaemic control and its associated factors in patients with type 2 diabetes across Europe: data from the PANORAMA study. Clinical endocrinology 2014, 80(1):47-56.

45. Ramachandran A, Snehalatha C, Shetty AS, Nanditha A. Trends in prevalence of diabetes in Asian countries. World J Diabetes. 2012; 3(6):110-117. doi:10.4239/wjd.v3.i6.110.

46. Chan JC, Gagliardino JJ, Baik SH, Chantelot JM, Ferreira SR, Hancu N, Ilkova H, Ramachandran A, Aschner P. Multifaceted determinants for achieving glycemic control: the International Diabetes Management Practice Study (IDMPS) Diabetes Care. 2009; 32:227-233.

47. AJMC Managed markets network. Challenges in Diabetes Management: Glycemic Control, Medication Adherence, and Healthcare Costs. Published on: August 21, 2017. https://www.ajmc.com/journals/supplement/2017/challenges-indiabetes-management/challenges-in-diabetes-management-article (accessed 12 july, 2019).

48. Alberti G, Zimmet P, Shaw J, Bloomgarden Z, Kaufman F, Silink M: Type 2 Diabetes in the Young: The Evolving Epidemic. The International Diabetes Federation Consensus Workshop 2004, 27(7):1798-1811.

49. Reinehr T. Type 2 diabetes mellitus in children and adolescents. World J Diabetes. 2013;4(6):270-281. doi:10.4239/wjd.v4.i6.270.

50. Prasad AN: Type 2 diabetes mellitus in young need for early screening. Indian pediatrics 2011, 48(9):683-688.

51. Temneanu OR, Trandafir LM, Purcarea MR. Type 2 diabetes mellitus in children and adolescents: a relatively new clinical problem within pediatric practice. J Med Life. 2016;9(3):235-239.

52. Zin Zin Htike, David Webb, Kamlesh Khunti and Melanie Davies. Emerging epidemic and challenges of Type 2 diabetes in young adults. Diabetes Manag. (2015) 5(6), 473-483. 
53. Kautzky-Willer A, Harreiter J, Pacini G. Sex and Gender Differences in Risk, Pathophysiology and Complications of Type 2 Diabetes Mellitus. Endocr Rev. 2016;37(3):278-316. doi:10.1210/er.2015-1137.

54. Færch, Kristine. Gender and T2DM [internet]. 2014 Aug 13; Diapedia 3104972816 rev. no. 10. Available from, https://www.diapedia.org/3104972816/rev/10.

55. Nordström A, Hadrévi J, Olsson T, Franks PW, Nordström P: Higher Prevalence of Type 2 Diabetes in Men Than in Women Is Associated With Differences in Visceral Fat Mass. The Journal of Clinical Endocrinology \& Metabolism 2016, 101(10):37403746.

56. Hilawe EH, Yatsuya H, Kawaguchi L, Aoyama A: Differences by sex in the prevalence of diabetes mellitus, impaired fasting glycaemia and impaired glucose tolerance in sub-Saharan Africa: a systematic review and meta-analysis. Bull World Health Organ. 2013 Sep 1;91(9):671-682D. doi: 10.2471/BLT.12.113415.

57. Sasi ST, Kodali M, Burra KC, Muppala BS, Gutta P, Bethanbhatla MK. Self-Care Activities, Diabetic Distress and other Factors which Affected the Glycaemic Control in a Tertiary Care Teaching Hospital in South India. Journal of Clinical and Diagnostic Research. 2013; 7(5): 857-860

58. Benoit SR, Fleming R, Philis-Tsimikas A, Ji M. Predictors of glycemic control among patients with Type 2 diabetes: a longitudinal study. BMC Public Health. 2005; 17(5):36.

59. Alramadan Mohammed J, Magliano Dianna J, Almigbal Turky H, Batais Mohammed A, Afsana Afroz, Alramadhan Hesham $\mathrm{J}$ et al Glycemic control for people with type 2 diabetes in Saudi Arabia-an urgent need for a review of management plan. BMC Endocrine Disorders. 2018; 18:62

60. Peng K, Chen G, Liu C., Mu Y, Ye Z, Shi L. etal Association between smoking and glycemic control in diabetic patients: Results from the Risk Evaluation of cancers in Chinese diabetic Individuals: A longitudinal (REACTION) study. Journal of Diabetes, 2018; 10: 408-418.

61. Willi C, Bodenmann P, Ghali WA, Faris PD, Cornuz J. Active smoking and the risk of type 2 diabetes: a systematic review and meta-analysis. JAMA. 2007; 298:2654-2664.

62. Ohkuma T, Iwase M, Fujii H, Kaizu S, Ide H, Jodai T et al. Dose- and Time-Dependent Association of Smoking and Its Cessation with Glycemic Control and Insulin Resistance in Male Patients with Type 2 Diabetes Mellitus: The Fukuoka Diabetes Registry. PLOS ONE. 2015; 10(3): e0122023.

63. Barrett-Connor E, Khaw KT. Cigarette smoking and increased central adiposity. Ann Intern Med. 1989; 111:783-787.

64. Dagogo-Jack S. DCCT Results and Diabetes Care in Developing Countries. Diabetes Care. 1995;18:416-17.

65. King H., Aubert R. E., Herman W. H. Global Burden of Diabetes. Prevalence, Numerical Estimates and Projections. Diabetes Care. 1998; 21:1414-31.

66. Yudkin J. S. Insulin for the World's Poorest Countries. Lancet. 2000; 355:919-21.

67. Amoah A. G., Owusu S. K., Saunders J. T., Fang W. L., Asare H. A., Pastors J. G., Sanborn C., Barrett E. J., Woode M. K., Osei K. Facilities and Resources for Diabetes Care at Regional Health Facilities in Southern Ghana. Diabetes Research and Clinical Practice. 1998; 42:123-30.

68. Dagogo-Jack S. DCCT Results and Diabetes Care in Developing Countries. Diabetes Care. 1995;18:416-17.

\section{Tables}

Table 1: Socio-demographic characteristics of type 2 diabetes patients at NRH, $2018(n=228)$ 


\begin{tabular}{|c|c|c|c|}
\hline Variables & Categories & Frequency (n) & Percentage (\%) \\
\hline \multirow[t]{2}{*}{ Sex } & Male & 118 & 51.8 \\
\hline & Female & 110 & 48.2 \\
\hline \multirow[t]{4}{*}{ Age } & $<21$ years & 9 & 3.9 \\
\hline & $21-40$ years & 80 & 35.1 \\
\hline & 41-60 years & 105 & 46.1 \\
\hline & $>60$ years & 34 & 14.9 \\
\hline \multirow[t]{4}{*}{ Religion } & Protestant & 111 & 48.7 \\
\hline & Orthodox & 76 & 33.3 \\
\hline & Muslim & 38 & 16.7 \\
\hline & Others & 3 & 1.3 \\
\hline \multirow[t]{4}{*}{ Marital status } & Married & 159 & 69.7 \\
\hline & Single & 17 & 7.5 \\
\hline & Divorced & 17 & 7.5 \\
\hline & Widowed & 35 & 15.4 \\
\hline \multirow[t]{3}{*}{ Ethnicity } & Oromo & 192 & 84.2 \\
\hline & Amhara & 23 & 10.1 \\
\hline & Gurage & 13 & 5.7 \\
\hline \multirow[t]{5}{*}{ Educational level } & Unable to read and write /illiterate & 63 & 27.6 \\
\hline & Informal education (able to read and write) & 51 & 22.4 \\
\hline & Primary level & 46 & 20.2 \\
\hline & Secondary level & 37 & 20.2 \\
\hline & college/university & 31 & 13.6 \\
\hline \multirow[t]{5}{*}{ Occupation } & Unemployed & 66 & 28.9 \\
\hline & Employed & 36 & 15.8 \\
\hline & Farmer & 73 & 32 \\
\hline & Merchant & 7 & 3.1 \\
\hline & Daily labor & 46 & 20.2 \\
\hline \multirow[t]{6}{*}{ Income (Ethiopian birr) } & $<500$ birr & 137 & 60.1 \\
\hline & 501-1000 birr & 49 & 21.5 \\
\hline & 1001-1500 birr & 7 & 3.1 \\
\hline & 1501-2000 birr & 5 & 2.2 \\
\hline & 2001-2500 birr & 3 & 1.3 \\
\hline & $>2500$ birr & 27 & 11.8 \\
\hline
\end{tabular}

Table 2: Self-care behaviors of the Type 2 DM patients at NRH, 2018 


\begin{tabular}{llll} 
Variables & & Number & Percent \\
\hline Compliance to healthful diet program in last seven days & $>3$ days (adequate) & 74 & 32.5 \\
\cline { 2 - 4 } & $0-3$ days (inadequate) & 154 & 67.5 \\
\hline Planned physical exercise in last seven days & $>3$ days (adequate) & 35 & 15.4 \\
\cline { 2 - 4 } & $0-3$ days (inadequate) & 193 & 84.6 \\
\hline Compliance to blood sugar testing in last three months & $\geq 3$ month (adequate) & 154 & 67.5 \\
\cline { 2 - 4 } & $0-3$ month (inadequate) & 74 & 32.5 \\
\hline Compliance to medication in last seven days & 7 days (adequate) & 148 & 64.9 \\
\cline { 2 - 4 } & $<7$ days inadequate & 80 & 35.1 \\
\hline Smoking & Yes & 15 & 6.6 \\
\cline { 2 - 4 } & No & 213 & 93.4 \\
\hline Drinking alcohol & Yes & 30 & 13.2
\end{tabular}

Table 3: Multivariable logistic regression analysis of factors associated with poor glycemic control among type 2 DM glycemic control at NRH, 2018 


\begin{tabular}{|c|c|c|c|c|c|c|c|}
\hline \multirow[t]{2}{*}{ Variable } & & \multicolumn{2}{|l|}{ Glycemic level } & \multicolumn{2}{|l|}{ COR } & \multicolumn{2}{|c|}{ AOR } \\
\hline & & Poor/uncontrolled & $\begin{array}{l}\text { Good/ } \\
\text { Controlled }\end{array}$ & $95 \% \mathrm{Cl}$ & $\begin{array}{l}\mathrm{P} \text { - } \\
\text { value }\end{array}$ & $95 \% \mathrm{Cl}$ & P-value \\
\hline \multirow[t]{2}{*}{ Sex } & Male & 65 & 53 & $0.40(0.23-0.50)$ & $0.221^{\star}$ & $\begin{array}{l}0.32 \\
(1.63- \\
20.19)\end{array}$ & 0.365 \\
\hline & Female & 83 & 27 & 1 & 1 & 1 & 1 \\
\hline \multirow[t]{4}{*}{ Age } & $<21$ years & 9 & 5 & $1.42(0.14-2.77)$ & 0.542 & $\begin{array}{l}1.32 \\
(0.09- \\
38.04)\end{array}$ & 0.505 \\
\hline & $21-40$ & 51 & 29 & $1.39(0.61-3.14)$ & 0.431 & $\begin{array}{l}1.21 \\
(0.03- \\
1.49)\end{array}$ & 0.119 \\
\hline & $41-60$ & 74 & 31 & $1.88(0.15-0.48)$ & $0.119 *$ & $\begin{array}{l}2.01 \\
(0.04- \\
0.06)\end{array}$ & 0.044 ** \\
\hline & $>60$ & 19 & 15 & 1 & 1 & 1 & 1 \\
\hline \multirow[t]{5}{*}{ Educational level } & $\begin{array}{l}\text { unable to read } \\
\text { and write } \\
\text { /illiterate }\end{array}$ & 49 & 14 & 3. 28 (1.56-9.94) & $0.001^{*}$ & $\begin{array}{l}3.12 \\
(1.52- \\
8.50)\end{array}$ & $0.001^{\star *}$ \\
\hline & Informal & 35 & 16 & $2.05(1.54-13.75)$ & $0.020 *$ & $\begin{array}{l}2.28 \\
(2.14- \\
32.60)\end{array}$ & 0.024 ** \\
\hline & primary & 28 & 18 & $1.12(0.94-1.34)$ & 0.231 & $\begin{array}{l}1.03 \\
(0.64- \\
2.14)\end{array}$ & 0.431 \\
\hline & Secondary & 25 & 12 & $1.46(0.55-3.78)$ & 0.454 & $\begin{array}{l}1.04 \\
(0.26- \\
17.48)\end{array}$ & 0.477 \\
\hline & college/university & 16 & 15 & 1 & 1 & 1 & 1 \\
\hline \multirow{3}{*}{$\begin{array}{l}\text { Duration } \\
\text { treatment }\end{array}$} & $<5$ years & 40 & 34 & 1 & 1 & 1 & 1 \\
\hline & $5-10$ years & 63 & 39 & $1.37(0.15-0.47)$ & 0.454 & $\begin{array}{l}1.19 \\
(1.06- \\
26.24)\end{array}$ & 0.642 \\
\hline & $>10$ years & 41 & 11 & $3.16(0.21-0.54)$ & $0.002^{*}$ & $\begin{array}{l}3.94 \\
(1.51- \\
27.83)\end{array}$ & $0.012^{\star \star}$ \\
\hline \multirow{3}{*}{$\begin{array}{l}\text { Treatment } \\
\text { Regimen }\end{array}$} & $\mathrm{OHA}$ & 88 & 48 & 1 & 1 & 1 & 1 \\
\hline & $\mathrm{OHA}+$ Insulin & 34 & 19 & $0.98(0.43-0.95)$ & $0.221^{*}$ & $\begin{array}{l}0.67 \\
(1.01- \\
14.40)\end{array}$ & 0.213 \\
\hline & Insulin only & 26 & 13 & $1.09(0.36-2.14)$ & 0.802 & $\begin{array}{l}1.05 \\
(0.02- \\
48.73)\end{array}$ & 0.982 \\
\hline \multirow[t]{2}{*}{$\begin{array}{l}\text { Healthful eating } \\
\text { plan }\end{array}$} & $0-3$ days & 104 & 50 & $1.42(0.80-2.52)$ & $0.233^{\star}$ & $\begin{array}{l}1.82 \\
(0.31- \\
2.15)\end{array}$ & 0.679 \\
\hline & >=3 day & 44 & 30 & 1 & 1 & 1 & 1 \\
\hline $\begin{array}{l}\text { Exercise/planned } \\
\text { aerobic physical } \\
\text { activity }\end{array}$ & 0-3 days & 133 & 60 & $2.96(1.42-6.17)^{\star}$ & 0.004 & $\begin{array}{l}3.19 \\
(1.05- \\
19.84)\end{array}$ & $0.019 * \star$ \\
\hline
\end{tabular}




\begin{tabular}{|c|c|c|c|c|c|c|c|}
\hline & $>=3$ days & 15 & 20 & 1 & 1 & 1 & 1 \\
\hline \multirow{2}{*}{$\begin{array}{l}\text { Blood glucose } \\
\text { test }\end{array}$} & Yes & 43 & 31 & 1 & 1 & 1 & 1 \\
\hline & No & 95 & 59 & $1.16(1.86-3.86)$ & $0.143^{\star}$ & $\begin{array}{l}1.83 \\
(0.34- \\
3.19)\end{array}$ & 0.954 \\
\hline \multirow[t]{2}{*}{ Smoking } & Yes & 13 & 2 & $3.76(0.13-0.98)$ & $0.087^{\star}$ & $\begin{array}{l}4.51 \\
(0.00- \\
0.50)\end{array}$ & $0.022^{\star *}$ \\
\hline & No & 135 & 78 & 1 & 1 & 1 & 1 \\
\hline \multirow[t]{2}{*}{$\begin{array}{l}\text { Alcohol } \\
\text { consumption }\end{array}$} & Yes & 22 & 8 & $1.57(1.66-11.71)$ & $0.203^{\star}$ & $\begin{array}{l}1.44 \\
(1.24- \\
19.02)\end{array}$ & 0.177 \\
\hline & No & 126 & 72 & 1 & 1 & 1 & 1 \\
\hline
\end{tabular}

AOR: adjusted odds ratio; COR: Crude odds ratio: OHA: Oral hypoglycemic agents

Note *Shows statistically significant at $p$ value $<0.25$.

** Shows statistically significant at $p$ value $<0.05$.

\section{Supplementary Files}

This is a list of supplementary files associated with this preprint. Click to download.

- eq1.jpg

- datacollectiontool.docx 